\title{
Use of Data Loggers to Investigate Temperature Trends Above and Below Cover Objects used by Plethodontid Salamanders
}

\author{
Emily Coscomb, Talon Abrams, Margaret Augustine, Samuel Casler, Phillip Keville, Collin Sullivan, and Eric H. Diefenbacher
}

SUNY Morrisville, P.O. Box 901, 80 Eaton St., Morrisville, New York 13408, USA (diefeneh@morrisville.edu)

\begin{abstract}
Amphibians utilize microhabitats to find refugia that will keep them functioning properly by regulating thermoregulatory behavior and for respiration. Microclimates of cover objects and the influence they may have in the selection of refugia by plethodontid salamanders are inherently difficult to study over long periods of time. Herein we provide a case study in which we used U23-003 HOBO Pro v2 2X Temperature Data Loggers to investigate temperature trends under and above cover objects selected by plethodontid salamanders in the field. Overall, data loggers were user-friendly for setup, deployment, and data offload and provided abundant data.
\end{abstract}

$\mathrm{T}$ emperature and humidity are the governing forces of amphibian life. For salamanders and other amphibians that are ectothermic, the temperature of the surrounding environment is especially vital to their survival (Feder and Londos 1984; Huey 1991). Amphibians operate best at low, stable temperatures that keep them far from critical maxima as well as lessening the thermoregulatory burden. Lower temperatures also aid in cutaneous respiration, especially for plethodontid salamanders, where moisture plays a crucial role (Gatz et al. 1975; Spotila 1972). Therefore, amphibians should pursue microhabitats that provide a stable, cool, and moist environment.

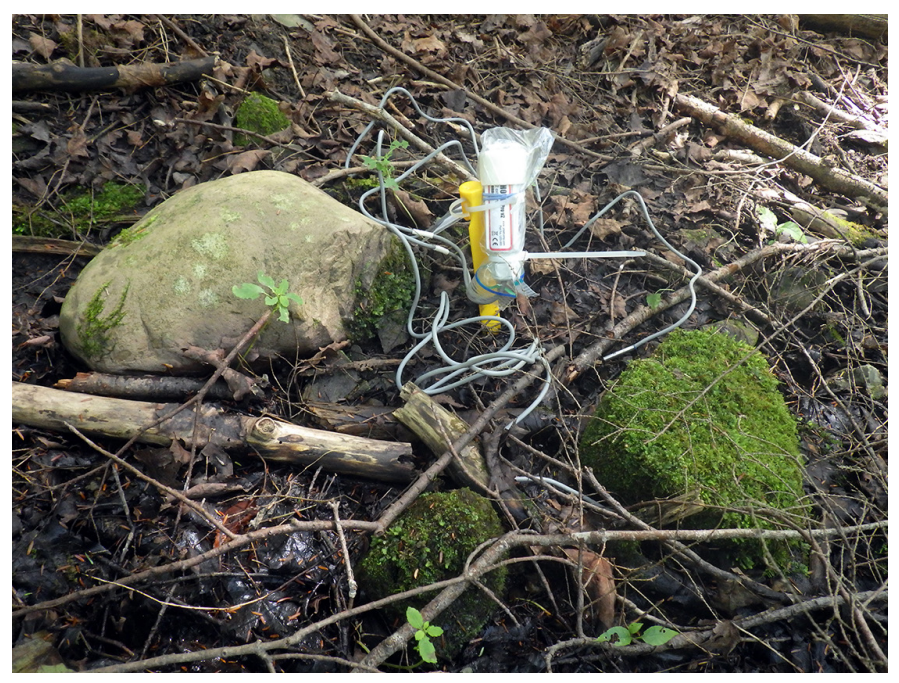

Fig. 1. A data logger setup in the field used during this study.
The role of plethodontid salamanders in their respective environments makes them ideal for monitoring forest system integrity (Best and Welsh 2014; Semlitsch et al. 2014; Welsh 2001). Additionally, climate change will cause dramatic challenges for amphibian populations that include finding suitable habitat (Milanovich et al. 2001; Raxworthy et al. 2008; Walther et al. 2002) and a need for morphological adaptations (Caruso et al. 2014). In the wake of these changes, increased emphasis has been placed on investigating the mitigating effects microhabitat refugia have for amphibians that utilize them (Seebacher and Alford 2002; Shoo et al. 2011). However, to date very few studies (e.g., Riddell and Sears 2015; Farallo and Miles 2016) have investigated the actual temperature trends that occur beneath cover objects chosen by plethodontid salamanders. One objective of our study was to determine if a U23-003 HOBO Pro v2 2X Temperature Data Logger was suitable for determining simultaneous temperature trends above and below cover objects utilized by plethodontid salamanders. The other objective was to see if temperature trends could be identified based on the data collected by the data loggers. These data loggers were chosen for their compact size and double-thermocouple-probe design, which allows two readings to be recorded and stored simultaneously in one device.

Materials and Methods

Logger setup.-Using HOBOware software (version 3.7.11), we programmed our U23-003 HOBO Pro v2 2X Temperature Data Loggers (ONSET Computer Corporation 


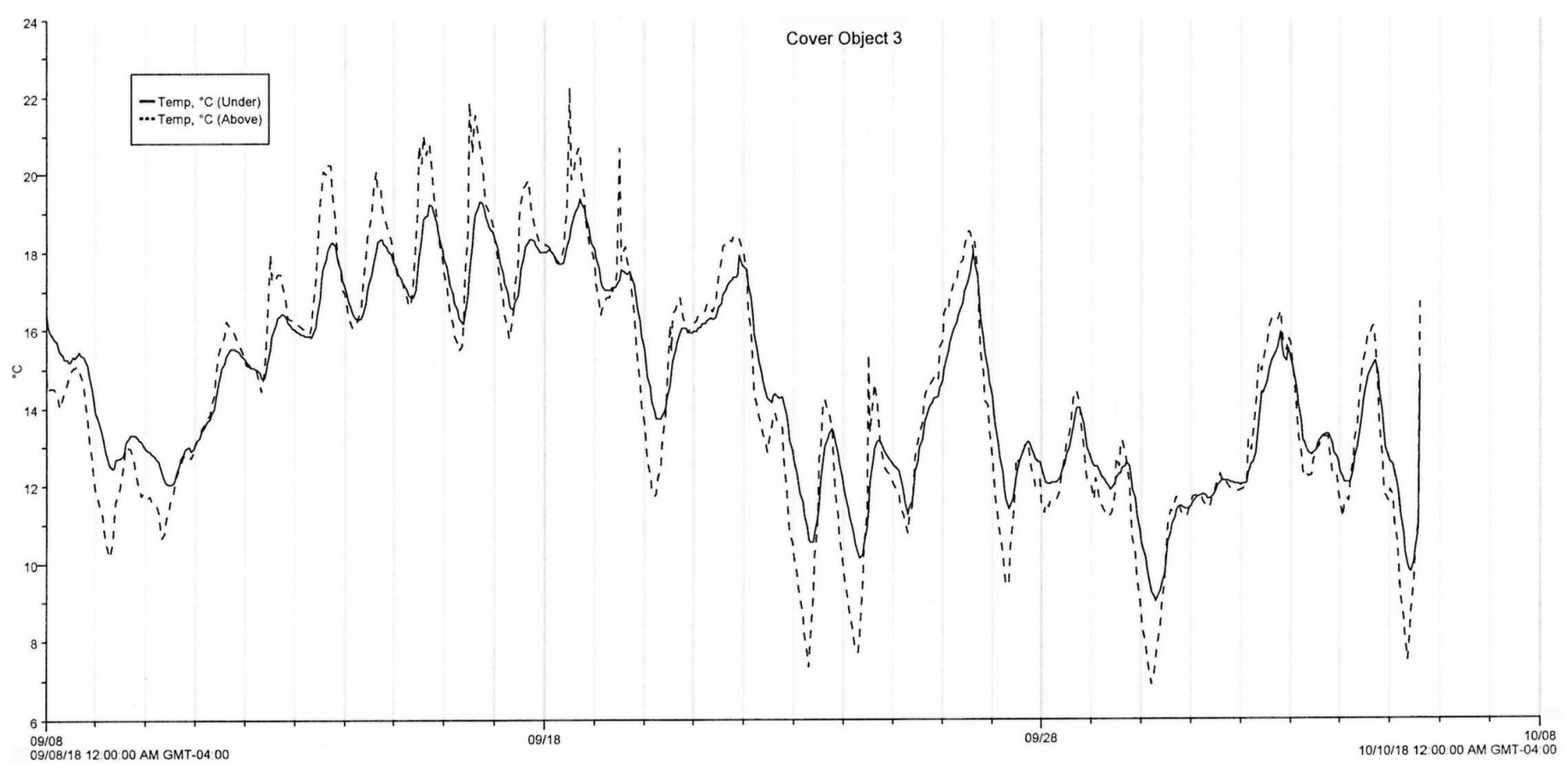

Fig. 2. An example of the output graph generated in the HOBOware software showing data from a 27-day deployment.

Bourne, MA) and deployed them in the Owens West Wildlife Management Area (WMA), Morrisville, New York. All four data loggers were given a unique label for identification purposes. The dual-channel probes were labeled "under" and "above," with the channel 1 probe labeled "under" as it was utilized to measure the temperature under a cover object, and the channel 2 probe labeled "above" because it was used to measure the temperature outside of a cover object. Loggers were set to record temperatures $\left({ }^{\circ} \mathrm{C}\right)$ every hour from 8 September 2018 through 5 October 2018.

In the field, we used randomized visual encounter surveys to find plethodontid salamanders. Once found, a salamander was removed from under its cover object and placed in a small sealable plastic bag containing a dampened paper towel. The salamander was contained until it could be measured for snout-to-vent length (SVL) and identified. These data were recorded along with the thickness of the cover object, which we measured using tree calipers.
Data loggers were deployed with the channel 1 probe placed as near to where the salamander was discovered under the corresponding cover object as possible. The cover object was then returned as found. Then the channel 2 probe was placed next to the cover object exposed to the surrounding atmosphere without cover. The body of the data logger was sealed in a plastic bag to prevent excessive precipitation from entering and attached to a stake next to the cover object (Fig. 1).

Study Area.-Owens West WMA is a 97-acre plot that is mostly a mixed hardwood forest surrounding a swampy area and a wetland field. Owens West WMA is located less than one mile south of the SUNY Morrisville campus. It is traditionally a non-consumptive area dedicated to management of game and non-game species. Due to the diverse habitat types situated in the area, it is utilized by the college as a forestry and wildlife laboratory.

Data Offload.-Upon retrieval, cover objects were examined for salamanders, data loggers collected, and then

Table 1. Environmental data taken at each deployment site.

\begin{tabular}{lccc} 
Species & $\begin{array}{c}\text { SVL } \\
(\mathbf{m m})\end{array}$ & $\begin{array}{c}\text { Cover } \\
\text { Object Type }\end{array}$ & $\begin{array}{c}\text { Average Cover Object } \\
\text { Thickness }(\mathbf{c m})\end{array}$ \\
\hline Plethodon cinereus & 27.3 & Log & 14.0 \\
\hline Plethodon cinereus & 29.6 & Rock & 6.5 \\
\hline Desmognathus ochropheaus & 35.8 & Rock & 7.8 \\
\hline Desmognathus fuscus & 52.7 & Rock & 5.3 \\
\hline
\end{tabular}




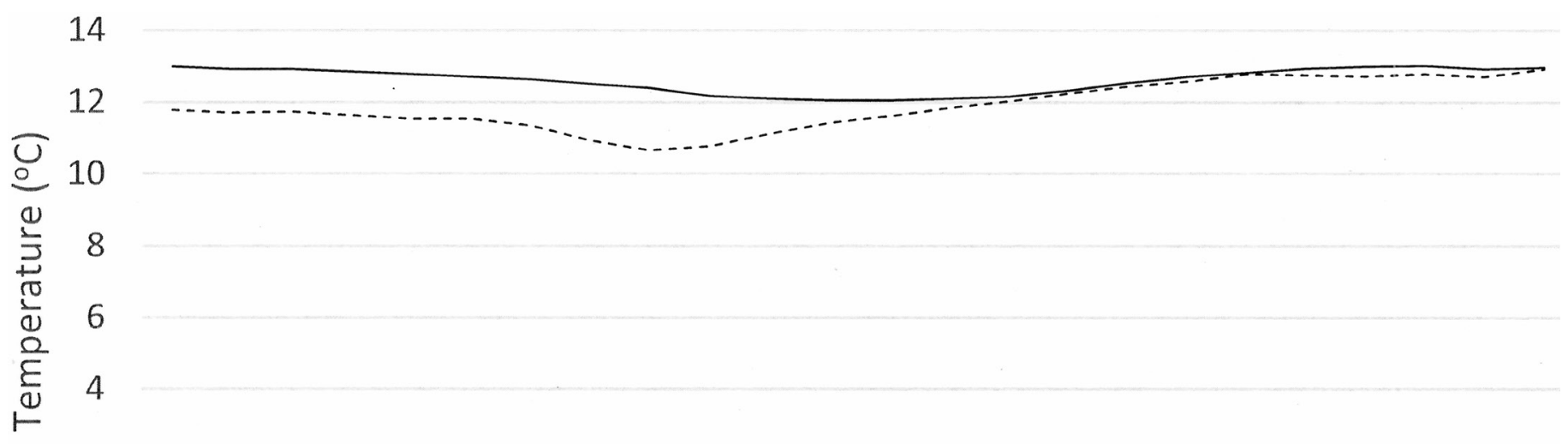

2

0

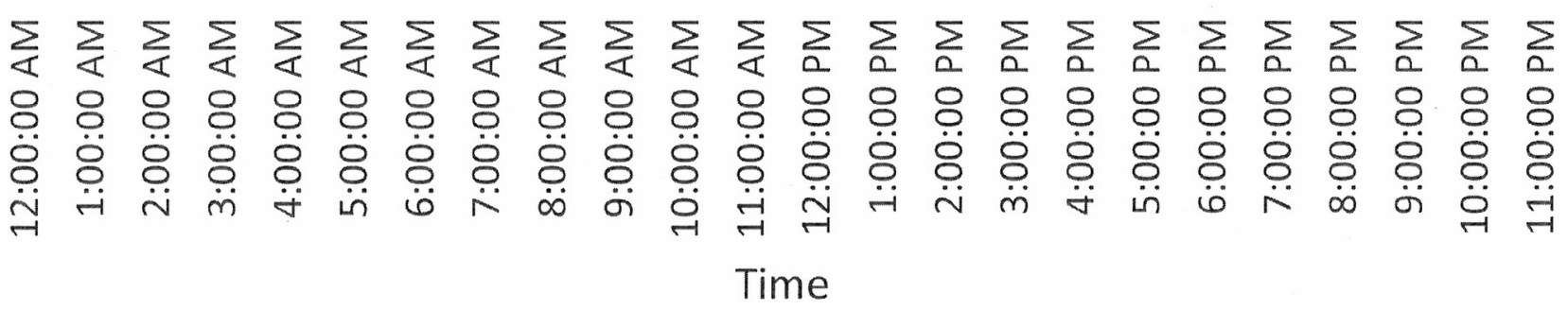

Fig. 3. Comparison of temperature trends from under a cover object (solid line) and above a cover object (dashed line) over a 24 -hour period on 10 September 2018.

returned to the laboratory. Loggers were stopped and read using the HOBOware software and HOBO optic USB base station and respective coupler. After a quick inspection in the $\mathrm{HOBO}$ ware software, data were exported to $\mathrm{Excel}^{\odot}$ for further analysis.

\section{Results}

Two adult Northern Redback Salamanders (Plethodon cinereus), one adult Allegheny Dusky Salamander (Desmognathus ochrophaeus), and one Northern Dusky Salamander (Desmognathus fuscus) of undetermined gender were collected from under either a rock or log with average thicknesses ranging from $5.3 \mathrm{~cm}$ to $14.0 \mathrm{~cm}$ (Table 1). All were under partial canopy cover.

The HOBOware software generated a graph and data table that were easy to read and showed all data points across the duration of deployment (Fig. 2). However, the HOBOware software lacked the ability to manipulate and refine the raw data, which is why all data were exported to Excel $^{\odot}$ to complete analyses.

A total of 2,652 data points were logged collectively by the four loggers. Of these, 1,496 data points were usable. Three of the four data loggers had wires severed by an unknown source (presumably some species of wildlife), which accounted for the reduction in usable data points. One logger recorded for 16 hours, two loggers recorded for 17 days, and one logger recorded for the full duration of deployment at 27 days
15 hours. Manipulating the data in $\operatorname{Excel}^{\odot}$ made it possible to view 24-hour temperature trends on a daily basis (Fig. 3). Averaging 24-hour trends produced a daily average temperature that could then be used to view general trends over the length of the data logger deployment (Fig. 4). Temperature trends of all loggers showed a close relationship between the rise and fall of temperatures above and beneath the cover object with the temperature underneath the cover object staying cooler than above the cover object on most days.

\section{Discussion}

Given the small sample size of loggers deployed, more meaningful statistical analysis could not be achieved. However, data gathered during this study did produce hour-by-hour comparisons of the simultaneous temperature trends above and below cover objects using the same logger. This eliminated the need to calibrate two separate loggers to achieve the same results. Programming the logger to take readings on an hourly basis does generate a quantity of data that can be daunting to sort. Logging intervals in the HOBOware software range from $1 \mathrm{sec}$ to $12 \mathrm{~h}$ with an additional custom option that we assume could make these loggers very adaptable to many different field applications where readings do not have to occur on an hourly basis. The ability to program the loggers to start taking readings on a specific date and time was very convenient and reduced the stress of having to find, collect, measure, deploy, and release salamanders in a confined span 


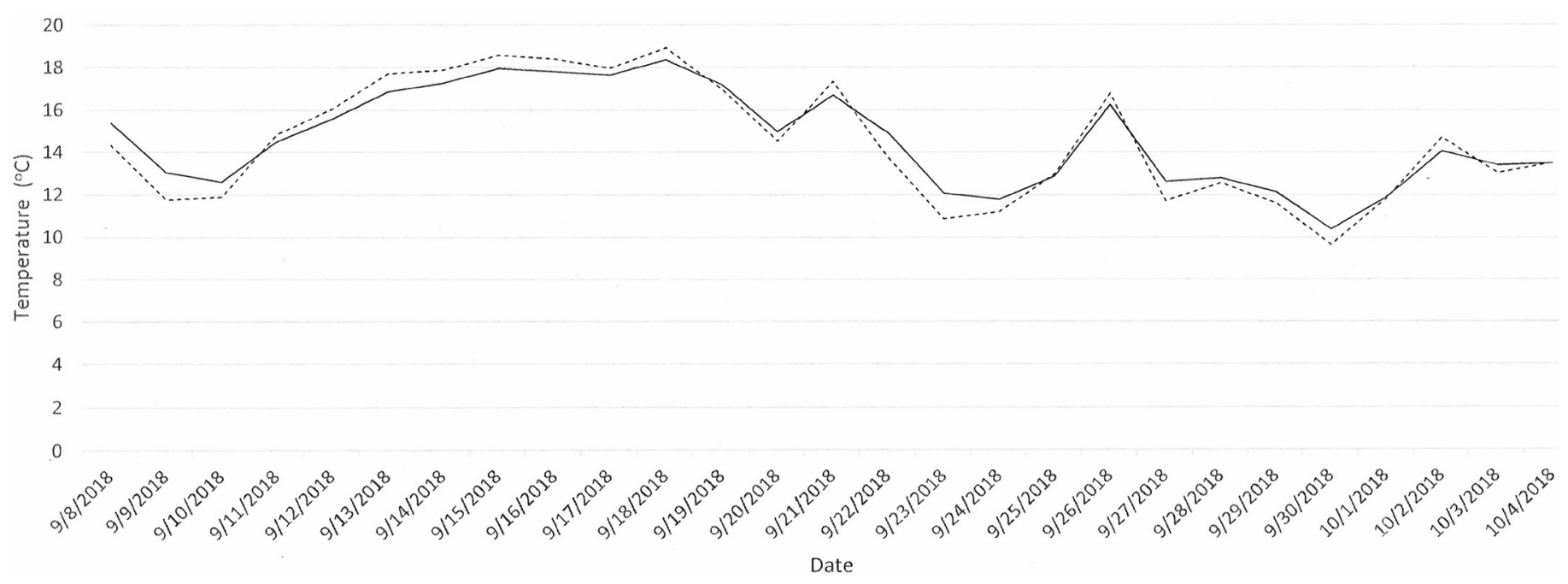

Fig. 4. Comparison of daily average temperatures under the cover object (solid line) and above the cover object (dashed line) over a 27-day deployment.

of time. This also reduced the number of data points that needed to be deleted.

We highly recommend that a wire cage or other barrier be placed over the loggers and probe wires to prevent tampering by wildlife. A simple enclosure made of hardware cloth could be easily constructed and anchored into place. Hardware cloth would allow for normal temperature, air currents, and moisture levels to fluctuate and salamanders to move freely while excluding larger wildlife. If an enclosure is not possible, insulating the probe wires in a type of hard plastic or metal shroud could reduce tampering by wildlife. If measures are not taken to prevent wildlife tampering, then we suggest daily visual observation of data loggers.

This is the first report of U23-003 HOBO Pro v2 2X Temperature Data Loggers being used in the field to collect simultaneous temperature data under and above a cover object used by plethodontid salamanders. Michels-Boyce and Zani (2015) used these loggers in a laboratory setting on Sideblotched Lizards (Uta stansburiana), but no studies employed field application for amphibians. Temperature loggers have been used to study thermal aspects of microhabitats in salamanders before. For example, Kluber et al. (2009) used GPSE 301203 dual-temperature data loggers to investigate downed wood microclimates along streams and upslope from streams by placing probes alongside downed wood or by drilling into downed wood to get readings. Farallo and Miles (2016) used iButton temperature loggers placed $50 \mathrm{~cm}$ above the ground, at ground level, and 10,20, and $30 \mathrm{~cm}$ below the ground at one site for their investigation. Watling et al. (2011) used a single Hygrochron iButton data logger to measure temperature and humidity at ground level placed within $5 \mathrm{~m}$ of each trap array while investigating how the invasive Amur Honeysuckle (Lonicera maackii) alters amphibian communities. However, each of these studies uses data loggers outside or drilled into the refugia rather than direct placement under the cover object where the salamander resides. This would force the assumption that the temperature outside of the cover object is equal to that under the cover object, which may not apply. The loggers used in our study allow for simultaneous data recording of temperatures with probe placement directly underneath as well as above the cover object. This also suggests that temperature fluctuations of thermal refugia could be investigated on an individual refugia scale. Given both probes were connected to the same logger also means each cover object could be used as an independent replicate depending on the experimental design. This information could be increasingly useful in conservation efforts in land management for species as well as exsitu captive husbandry plans in the future (e.g., Michaels et al. 2014). Further research and application of these loggers could eventually help better understand cover-object choice based on microclimates and aid in conservation of plethodontid salamanders into the future.

\section{Acknowledgements}

This project was supported in part by contributions from SUNY High Impact Learning and Teaching (HILT) Hub and SUNY Morrisville Collegiate Science \& Technology Entry Program (CSTEP). Specimens were collected under NYSDEC license numbers 117 and 2026.

\section{Literature Cited}

Best, M.L. and H.H. Welsh. 2014. The trophic role of a forest salamander: Impacts on invertebrates, leaf litter retention, and the humification process. Ecosphere 5: 1-19.

Caruso, N.M., M.W. Sears, D.C. Adams, and K.R. Lips. 2014. Widespread rapid reductions in body size of adult salamanders in response to climate change. Global Climate Change Biology 20: 1751-1759.

Farallo, V.R. and D.B. Miles. 2016. The importance of microhabitat: A comparison of two microendemic species of Plethodon to the widespread P. cinereus. Copeia 2016: 67-77.

Feder, M.E., and P.L. Londos. 1984. Hydric contraints upon foraging in a terrestrial salamander, Desmognathus ochrophaeus (Amphibia: Plethodontidae). 
Oecologia 64: 413-418.

Gatz, R.N., E.C. Crawford, Jr., and J. Piiper. 1975. Kinetics of inert gas equilibration in exclusively skin-breathing salamander, Desmognathus fuscus. Respiratory Physiology 24: 15-29.

Huey, R.B. 1991. Physiological consequences of habitat selection. American Naturalist 137: S91-S115.

Kluber, M.R., D.H. Olson, and K.J. Puettmann. 2009. Downed wood microclimates and their potential impact on plethodontid salamander habitat in the Oregon Coast Range. Northwest Science 83: 25-34.

Michaels, C.J., B.F. Gini, and R.F. Preziosi. 2014. The importance of natural history and species-specific approaches in amphibian ex-situ conservation. Herpetological Journal 24: 135-145.

Michels-Boyce, M. and P.A. Zani. 2015. Lack of supercooling evolution related to winter severity in a lizard. Journal of Thermal Biology 53: 72-79.

Milanovich, J.R., W.E. Peterman, N.P. Nibbelink, and J.C. Maerz. 2010. Projected loss of a salamander diversity hotspot as a consequence of projected global climate change. PLoS ONE 5: e12189.

Raxworthy, C.J., R.G. Pearson, N. Rabibisoa, A.M. Rakotondrazafy, J.-B. Ramanamanjato, A.P. Raselimanana, S. Wu, R.A. Nussbaum, and D.A. Stone. 2008. Extinction vulnerability of tropical montane endemism from warming and upslope displacement: A preliminary appraisal for the highest massif in Madagascar. Global Change Biology 14: 1703-1720.

Riddell, E.A. and M.W. Sears. 2015. Geographic variation of resistance to water loss within two species of lungless salamanders: Implications for activity.
Ecosphere 6 (article 86): 1-16.

Seebacher, F. and R.A. Alford. 2002. Shelter microhabitats determine body temperature and dehydration rates of a terrestrial amphibian (Bufo marinus). Journal of Herpetology 36: 69-75.

Semlitsch, R.D., K.M. O’Donnell, and F.R. Thompson. 2014. Abundance, biomass production, nutrient content, and the possible role of terrestrial salamanders in Missouri Ozark forest ecosystems. Canadian Journal of Zoology 92: 997-1004.

Shoo, L.P., D.H. Olson, S.K. Mcmenamin, K.A. Murray, M. Van Sluys, M.A. Donnelly, D. Stratford, J. Terhivuo, A. Merino-Viteri, S.M. Herbert, P.J. Bishop, P.S. Corn, L. Dovey, R.A. Griffiths, K. Lowe, M. Mahony, H. Mccallum, J.D. Shuker, C. Simpkins, L.F. Skeratt, S.E. Williams, and J.-M. Hero. 2011. Engineering a future for amphibians under climate change. Journal of Applied Ecology 48: 487-492.

Spotila, J.R. 1972. Role of temperature and water in the ecology of lungless salamanders. Ecological Monographs 42: 95-125.

Walther, G.-R., E. Post, P. Convey, A. Menzel, C. Parmesan, T.J.C. Beebee, J.-M. Fromentin, O. Hoegh-Guldberg, and F. Bairlein. 2002. Ecological responses to recent climate change. Nature 416: 389-395.

Watling J.I., C.R. Hickman, and J.L. Orrock 2011. Invasive shrub alters native forest amphibian communities. Biological Conservation 144: 2597-2601.

Welsh, H.H. and S. Droege. 2001. A case for using plethodontid salamanders for monitoring biodiversity and ecosystem integrity of North American forests. Conservation Biology 15: 558-569. 